\title{
Interaction between diazepam and hippocampal corticosterone after acute stress: impact on memory in middle-aged mice
}

\section{Daniel Béracochéa ${ }^{* \dagger}$, Christophe Tronche ${ }^{1,2+}$, Mathieu Coutan ${ }^{2}$, Rodolphe Dorey ${ }^{1,2}$, Frédéric Chauveau ${ }^{2}$ and Christophe Piérard ${ }^{2}$}

1 UMR-CNRS 5287, Institut de Neurosciences Cognitives et Intégratives d'Aquitaine, Universités de Bordeaux, Talence, France

2 Département Environnements Opérationnels, Institut de Recherche Biomédicale des Armées, Brétigny sur Orge, France

\section{Edited by:}

Luke R. Johnson, Uniformed Services

University of the Health Sciences, USA

\section{Reviewed by:}

Gernot Riedel, University of Aberdeen, UK

Mouna Maroun, University of Haifa,

Israel

\section{*Correspondence:}

Daniel Béracochéa, UMR-CNRS 5287, Institut de Neurosciences Cognitives et Intégratives d'Aquitaine, Universités de Bordeaux, Bat B2, Avenue des Facultés, 33405 Talence cédex, France. e-mail:d.beracochea@

cnic.u-bordeaux1.fr

${ }^{\dagger}$ Daniel Béracochéa and Christophe Tronche share the first place in the list.
Benzodiazepines (BDZ) are widely prescribed in the treatment of anxiety disorders associated to aging. Interestingly, whereas a reciprocal interaction between the GABAergic system and HPA axis has been evidenced, there is to our knowledge no direct evaluation of the impact of BDZ on both hippocampus (HPC) corticosterone concentrations and HPC-dependent memory in stressed middle-aged subjects. We showed previously that an acute stress induced in middleaged mice severe memory impairments in a hippocampus-dependent task, and increased in parallel hippocampus corticosterone concentrations, as compared to non-stressed middle-aged controls (Tronche et al., 2010). Based on these findings, the aims of the present study were to evidence the impact of diazepam (a positive allosteric modulator of the GABA-A receptor) on HPC glucocorticoids concentrations and in parallel on HPC-dependent memory in acutely stressed middle-aged mice. Microdialysis experiments showed an interaction between diazepam doses and corticosterone concentrations into the HPC. From 0.25 to $0.5 \mathrm{mg} / \mathrm{kg}$, diazepam dose-dependently reduces intra-HPC corticosterone concentrations and in parallel, dose-dependently increased hippocampal-dependent memory performance. In contrast, the highest $(1.0 \mathrm{mg} / \mathrm{kg})$ diazepam dose induces a reduction in HPC corticosterone concentration, which was of greater magnitude as compared to the two other diazepam doses, but however decreased the hippocampal-dependent memory performance. In summary, our study provides first evidence that diazepam restores in stressed middle-aged animals the hippocampus-dependent response, in relation with HPC corticosterone concentrations. Overall, our data illustrate how stress and benzodiazepines could modulate cognitive functions depending on hippocampus activity.

Keywords: glucocorticoids, benzodiazepines, hippocampus, microdialysis, aging, stress

\section{INTRODUCTION}

It is well known that both stress-induced and age-induced cognitive dysfunctions are major public health issues nowadays. More particularly, it has been shown that stress and aging impair in humans declarative memory, and more specifically memory processes involving either the hippocampus (HPC) and/or prefrontal cortex activity (de Quervain et al., 2003; Cappell et al., 2010). Moreover, both stress-induced and aged-induced memory impairments would involved dysfunction of the HPA axis activity (Sapolsky et al., 1986; de Kloet et al., 1991; Lupien et al., 1999; Pardon, 2007; Pardon and Ratray, 2008; Comijs et al., 2010).

In line with these observations, we recently showed that stressed middle-aged mice exhibited contextual memory impairments associated with a dramatic increase in intra-HPC corticosterone concentration (Tronche et al., 2010a). We already evidenced the causal role of HPC corticosterone on memory dysfunction in stressed middle-aged mice insofar as the administration of metyrapone (an inhibitor of corticosterone synthesis) totally alleviated both the stress-induced corticosterone rise and memory impairments (Tronche et al., 2010a). In addition, we also showed that the direct infusion of corticosterone into the
HPC of young adult mice induced memory impairments similar to those observed in stressed middle-aged mice (Chauveau et al., 2009, 2010).

Because of the impact of benzodiazepines (BDZ) on GABAergic neurons, these compounds are widely prescribed in the treatment of anxiety disorders associated to aging. Indeed, it has been shown that aging causes organisms to become vulnerable to stress, which might be mediated by dysfunction of the brain system regulating emotional and stress responses (Pardon and Ratray, 2008; Shoji and Mizoguchi, 2010). However, it is also known that compounds modulating GABA-A receptors such as BDZ, also affect HPCdependent memory functions (for review, see Beracochea, 2006). Furthermore, it has already been demonstrated that GABAergic neurons also act on hypothalamic nuclei of the HPA axis (Jones et al., 1984; Hillhouse and Milton, 1989; Stotz-Potter et al., 1996; Cullinan et al., 2008) and that peripheral injection of GABA-A receptor positive modulators such as BDZ reduced HPA axis activity (Imaki et al., 1995; Grottoli et al., 2002).

Given the reciprocal interaction between the GABAergic system and HPA axis, it is of importance to determine the impact of BDZ administration on HPA axis activity and its consequence on memory 
function, in particular in middle-aged subjects that are vulnerable to stress. So far, the aim of the present study was to evidence more specifically the impact of BDZ administration on HPC glucocorticoids concentration and its consequence on memory in a HPCdependent contextual memory task in stressed middle-aged mice.

For that purpose, we studied in a first experiment the effects of a diazepam administration on contextual memory, using the contextual serial discrimination task (CSD). This task allowed to evidence a hippocampal-dependent memory impairment in stressed (Celerier et al., 2004; Piérard et al., 2009) as well as in middle-aged (Tronche et al., 2010a) and aged subjects (Tronche et al., 2010b). More precisely, the CSD task involves two serial discriminations (D1 and D2) learned on two different contexts. We found from in situ brain lesions and pharmacological experiments, that the memory retrieval of D1 but not of D2 is HPC-dependent (Chauveau et al., 2008, 2009, 2010). In a second experiment, we evaluated the emotional status of diazepamtreated stressed middle-aged mice in an elevated plus-maze task. Finally, in a third experiment, we measured by in vivo microdialysis the intra-HPC corticosterone concentration following diazepam administration in freely moving mice. Microdialysis allows a direct and dynamic measurement of the interaction between the HPA axis and the HPC, as a function of the administered dose of diazepam. Whereas peripheral measurements of circulating glucocorticoids have already been performed (Comijs et al., 2010), there is to our knowledge no direct evidence for such a dynamic interaction at the hippocampal level, which is surprising given the known importance of the hippocampus both in memory processes and in the negative feedback exerted by this brain area on HPA axis activity.

\section{MATERIALS AND METHODS \\ ANIMALS}

Upon arrival in the laboratory, all animals were 3-month-old male mice of the BALB/c inbred strain obtained from Charles River (L'Arbresle, France). Animals were housed in collective cage in the colony room ( $12 \mathrm{~h}$ light-dark cycle in a temperature controlled and ventilated room) until they were either 16 months. Two weeks before the experiments, they were housed individually. The animal's weights were ranged between 28 and $35 \mathrm{~g}$ at the time of experiments. All procedures were carried out during the light phase of the cycle, between 08:00 and 12:00 a.m. During the food deprivation phase, mice were handled daily so as to become familiar with the experimenter. During that phase, all subjects were maintained at 85-90\% of their ad libitum body weight throughout the behavioral study. All animal experimentation reported in the present paper has been conducted in accordance with the guidelines laid down by the European Communities Council.

\section{MEMORY TEST Apparatus}

The CSD has been extensively described in earlier studies (Chauveau et al., 2009, 2010; Pierard et al., 2010). All tests were performed in a four-hole board apparatus $(45 \mathrm{~cm} \times 45 \mathrm{~cm} \times 30 \mathrm{~cm}$ high $)$ enclosed by gray Plexiglas. The four-hole board apparatus was placed on the floor of the room $(3.0 \mathrm{~m} \times 3.0 \mathrm{~m} \times 2.40 \mathrm{~m}$ high $)$. The floor of the board was interchangeable (white and rough; black and smooth). On the floor, four holes opening on a food cup $(3 \mathrm{~cm}$ in diameter $\times 2.5 \mathrm{~cm}$ in depth) were located $6 \mathrm{~cm}$ away from the sidewalls. The apparatus was placed in a room exposed to a $60-\mathrm{dB}$ background noise and a light centered over the apparatus provided $20 \mathrm{~lx}$ intensity at the position of the apparatus. The apparatus was cleaned with 95\% ethanol, then with water before each mouse behavioral testing. Data were automatically monitored by photoelectric cells and video recording.

\section{Acquisition phase}

In the CSD, the acquisition phase took place in room A where animals learned two consecutive spatial discriminations (D1 and D2; see Figure 1). Both discriminations differed in terms of the color and texture of the floor (internal context of the four-hole board)

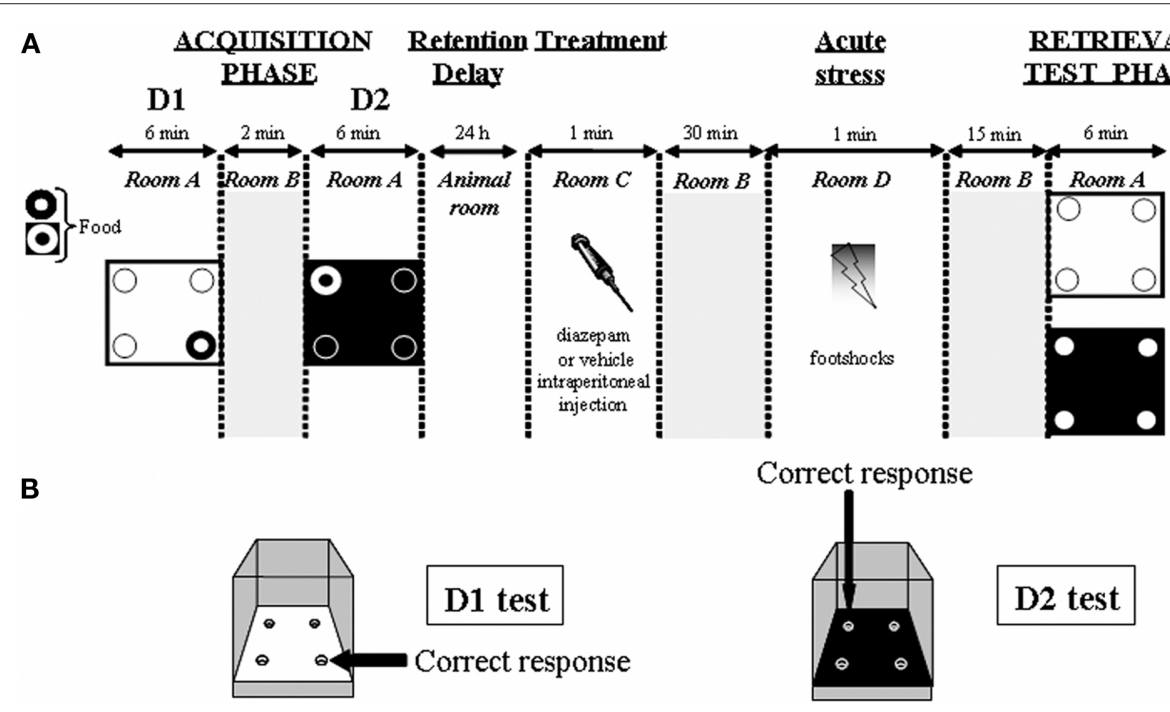

FIGURE 1 | Description of the contextual serial discrimination (CSD) behavioral task. (A) Behavioral procedures. (B) Type of responses for the retrieval test phase. D1, discrimination 1; D2, Discrimination 2; CSD, contextual serial discrimination. During retrieval test phase, each mice is randomly evaluated either on D1 floor or D2 floor without food reward. 
and were separated by a 2 -min delay interval. During this delay, the mouse was returned to its home cage in room $\mathrm{B}$. At the beginning of acquisition and retrieval phases, mice were placed in the center of the four-hole board in an opaque PVC tube for $5 \mathrm{~s}$ to provide the animal with a random start in the apparatus. For D1, ten 20-mg food pellets were available only in one of the four holes on the board for 6 min. Location of the baited hole for D1 was randomized for each subject. For D2, ten 20-mg food pellets were consistently located in the opposite symmetrical hole, for 6 min likewise. The environmental spatial cues were made of colored and striped paper sheets positioned at $1.00 \mathrm{~m}$ above the four-hole board. These allocentric cues remained at the same place for both D1 and D2 discriminations and for the retrieval phase. Thus, both discriminations D1 and D2 differed only by the internal (floor) contextual cues. Both floors were positioned in a mixed random order during the acquisition of the first and second discrimination tasks. At the end of the acquisition phase, mice returned to their home cage in the animal room for $24 \mathrm{~h}$. Only mice having eaten all the pellets during both acquisition sessions were used for the retrieval test phase.

\section{Acute stress}

Twenty-four hours after acquisition, mice were placed in the stress delivery cage for $1 \mathrm{~min}$, in room $\mathrm{D}$. Stress was induced $15 \mathrm{~min}$ before the test session. Stressed mice received three consecutive inescapable electric foot-shocks $(0.9 \mathrm{~mA} ; 10 \mathrm{~ms})$. All animals were then returned to their home cage during the delay preceding the test session.

\section{Test phase}

Fifteen minutes after acute stress, mice were replaced in the fourhole board (room A) without any pellet in the apparatus. Mice were placed either on the D1 floor or on the D2 floor and were allowed to freely explore the apparatus for $6 \mathrm{~min}$. For all mice, the retrieval test phase occurred $24 \mathrm{~h}$ after the acquisition phase and was performed on independent groups for either D1 or D2. Performance was assessed by measuring the number of head dips in each hole during 6 min.

\section{Measurements}

Memory retrieval performance was evaluated through the exploration rates into the different holes. Correct responses were defined as head dips into the hole previously baited on the same floor-context during the acquisition phase, and were calculated as follows: (head dips into the baited hole/total number of head dips in the four holes) $\times 100$.

\section{EVALUATION OF EMOTIONAL STATUS Elevated plus maze}

In order to verify the anxiolytic action of diazepam and the absence of sedative effect for the selected doses, stressed animals were submitted to the elevated plus-maze task 15 min after electric shock delivery. Stress was similar as the one previously described in the CSD experiments. The elevated plus maze, which was constructed of gray Plexiglas, consisted of four arms arranged in the shape of a plus sign. Each arm was $30 \mathrm{~cm}$ long, $7 \mathrm{~cm}$ wide, and was elevated $40 \mathrm{~cm}$ above the ground. The four arms were joined at the center by a 7-cm square platform. Two opposite arms of the plus maze were enclosed by sidewalls $17 \mathrm{~cm}$ high, but open on the top.
The remaining arms did not have sidewalls. These walls did not extend from the center of the maze. The experiment was performed between 08:30 and 12:00 a.m. At the beginning of the session, mice were placed at the center of the plus maze in a cylinder $(8 \mathrm{~cm}$ diameter, $17 \mathrm{~cm}$ high) for $30 \mathrm{~s}$. Then, the cylinder was removed and mice were allowed to freely explore all arms of the maze for $6 \mathrm{~min}$. An entry was counted only when a mouse entered an arm with all four paws. "Anxiety-like" behavior was measured by the ratio of entries into the open arms divided by the total number of entries in all arms (entry ratio). Results were expressed in percentages $($ ratio $\times 100)$. The elevated plus-maze test has been performed in four independent groups of mice (i.e., not submitted to the CSD task and microdialysis experiment) distributed as follows: vehicle: $n=7$; diazepam $0.25 \mathrm{mg} / \mathrm{kg}: n=7$; diazepam $0.5 \mathrm{mg} / \mathrm{kg}: n=7$; diazepam $1.0 \mathrm{mg} / \mathrm{kg}: n=7)$.

\section{SURGERY AND HISTOLOGY}

Mice were anesthetized with a ketamine (100 mg/kg body weigh)xylazine (10 mg/kg body weigh) mixture and placed into a stereotaxic frame. A single guide cannula microdialysis (CMA/7 Microdialysis probe, CMA Microdialysis, Sweden) was implanted in the bottom of the parietal cortex at the following coordinates from the bregma (Paxinos and Franklin, 2001): Antero-posterior $=-2000 \mu \mathrm{m}$, Lateral $=+1400 \mu \mathrm{m}$, and Vertical $=-800 \mu \mathrm{m}$. The guide cannula was fixed with dental cement and three micro screws attached to the skull. All operated mice were allowed to recover in their home cages in the animal room for at least 7 days before the microdialysis experiment. On the day of the experiment, the microdialysis probe was lowered $1 \mathrm{~mm}$ below through the guide cannula so that the microdialysis membrane is located into the dorsal HPC. At the end of the microdialysis experiment, mice were anesthetized and then transcardially perfused in the left ventricle with saline solution $(\mathrm{NaCl} 0.9 \%)$ followed by formaldehyde (4\%). Brains were then postfixed in a $4 \%$ formaldehyde solution for 10 days, then in a saccharose-formaldehyde solution (30 and 4\% v/v) for 2 days. All the brains were sectioned coronally ( $50 \mu \mathrm{m}$ thickness). A cresyl violet stain was used to locate the microdialysis probe with utmost accuracy.

\section{IN VIVO MICRODIALYSIS}

Seven days after surgery, a dialysis probe (CMA/7; CMA Microdialysis AB, Sweden; length: $1 \mathrm{~mm}$; molecular cut-off $6 \mathrm{kDa}$ and membrane outer diameter: $0.24 \mathrm{~mm}$ ) was carefully implanted into the right dorsal HPC under light anesthesia induced by a ketamine (50 mg/kg body weigh)-xylazine ( $5 \mathrm{mg} / \mathrm{kg}$ body weigh) mixture. Mice were then individually housed in a system allowing animals to move freely (CMA/120; CMA Microdialysis AB, Sweden) overnight. After the overnight perfusion at $1 \mu \mathrm{l} / \mathrm{min}$ to equilibrate extracellular metabolites concentrations, freely moving animals were continuously perfused with a sterile-filtered saline solution (Dulbecco's phosphate buffered saline; SIGMA; in g/l: $\mathrm{CaCl}_{2}, 0.133$; $\mathrm{MgCl}_{2}, 0.1 ; \mathrm{KCl}, 0.2 ; \mathrm{KH}_{2} \mathrm{PO}_{4}, 0.2 ; \mathrm{NaCl} 8.0 ; \mathrm{Na}_{2} \mathrm{HPO}_{4}, 1.15 ; \mathrm{pH}$ between 7.1 and 7.5 ) at a $1-\mu \mathrm{l} / \mathrm{min}$ flow rate through a micro-infusion pump. The foot-shock delivery system was inside the dialysis cage in order to deliver acute stress. Microdialyzates were sampled every 15 min using tubes with a dead volume of $1.2 \mu \mathrm{l} / 100 \mathrm{~mm}$ length (CMA Microdialysis AB). Samples were stored at $-80^{\circ} \mathrm{C}$. 
Baseline dialyzates were collected for $1 \mathrm{~h}$ before ip injection of diazepam ( $n=8$ for each dose) or vehicle $(n=8)$ and 30 min before acute stress delivery. Free corticosterone levels measured in the dialyzate (in nanomolar) were expressed as the percentage of the averaged baseline values collected before the injection.

\section{DRUG ADMINISTRATION}

Five days before experiments, mice were daily prepared for intraperitoneal (ip) administration by exerting light pressure on the body with the syringe. On the day of the experiment, $30 \mathrm{~min}$ before acute stress administration, mice received an ip injection of a diazepam solution. Diazepam (Valium ${ }^{\circledast}$, Roche, 1, 0.5, $0.25 \mathrm{mg} / \mathrm{kg}$ body weigh dissolved in saline solution) and vehicle (saline solution) solutions were injected in a room (room C, Figure 1) different from the behavioral room (room A).

\section{INTRA-HIPPOCAMPAL CORTICOSTERONE ASSAY}

A commercially prepared Enzyme Immunoassay kit was used to measure HPC corticosterone concentrations in the microdialyzates (Correlate-EIA ${ }^{\mathrm{TM}}$, Assay Designs, Ann Arbor, USA). The sensitivity of the assay was $0.08 \mathrm{nmol} / \mathrm{l}$. Therefore, baseline sample concentration was more than 10 -fold superior than sensitivity threshold.

\section{STATISTICAL ANALYSES}

Statistical analyses were performed using the Sigma Plot 11.0 software. Behavioral data were analyzed using 1 way or 2 way factorial analyses of variance (ANOVAs) with either "Treatments" and "Discriminations" as factors followed, - when adequate, with post hoc comparisons (Bonferroni's t-test). In the CSD task, comparisons of retrieval performances with chance level were calculated with paired-samples $t$-test (with hypothesized mean $=$ chance level $=25 \%$ for correct responses).

For microdialysis, basal free extracellular corticosterone levels were compared with one sample Student's $t$-test. Stress effects on intra-HPC corticosterone levels are expressed in percentage of baseline variation. They were compared using two-way repeated-measures ANOVA (RM-ANOVA) with both "Treatments" and "Time" factors. When appropriate, post hoc analyses were performed with Bonferroni's $t$-test.
All the data were expressed as mean \pm SEM and "NS" means that " $p$ " values exceed 0.05 and are considered as non-statistically significant.

\section{ETHICAL STATEMENT}

The present study was carried out in compliance with the European Convention for the protection of Vertebrate Animals used for Experimental and other Scientific Purposes, under the agreement \#2010/11 delivered by the French Ministry of Defence after the protocol was examined by the local ethical committee. Guidelines for proper laboratory animal care were fully implemented.

\section{RESULTS \\ EXPERIMENT 1: CSD TASK Acquisition phase}

The acquisition phase has been analyzed according to the further random attribution of mice to D1 (Vehicle: $n=10 ; 0.25 \mathrm{mg} / \mathrm{kg}$ : $n=9 ; 0.5 \mathrm{mg} / \mathrm{kg}: n=9 ; 1.0 \mathrm{mg} / \mathrm{kg}: n=9$ ) or D2 (Vehicle: $n=10$; $0.25 \mathrm{mg} / \mathrm{kg}: n=9 ; 0.5 \mathrm{mg} / \mathrm{kg}: n=9 ; 1.0 \mathrm{mg} / \mathrm{kg}: n=9)$ as regards the retrieval test phase and the post-stress delay. Total numbers and percentage of head dips are reported in Table 1. The Student's $t$-test is used for comparisons between D1 and D2.

\section{Test phase}

A two-way ANOVA performed on all groups (vehicle; Diazepam $0.25 \mathrm{mg} / \mathrm{kg}$, Diazepam $0.5 \mathrm{mg} / \mathrm{kg}$, and Diazepam $1.0 \mathrm{mg} / \mathrm{kg}$ ) showed a significant interaction between Discriminations $\times$ Treatments $\left[F_{(3,66)}=33.049 ; p \leq 0.001\right.$; Figure 2].

(i) Vehicle. Vehicle-treated mice exhibited performance for D1 and D2 significantly different from chance level (25\%; $17.8 \pm 2.5 \% ; t=3.552 ; p \leq 0.01$ and $46.3 \pm 2.5 \% ; t=8.663$; $p \leq 0.001$ respectively as compared to chance level). Bonferroni's $t$-test reveals significant memory performances differences between D1 and D2 (17.8 \pm 2.5 and $46.3 \pm 2.5 \%$ respectively; $t=8.218 ; p \leq 0.001)$.

(ii) Diazepam $0.25 \mathrm{mg} / \mathrm{kg}$. Within-group analyses showed that D1 performance in $0.25 \mathrm{mg} / \mathrm{kg}$ treated mice was at chance $(28.7 \pm 5.7 \% ; t=1.943$; NS) but was significantly above

Table 1 | Total number of head dips and \% number of head dips in the rewarded hole of acquisition 1 and acquisition 2 in vehicle and diazepamtreated groups.

\begin{tabular}{|c|c|c|c|c|c|c|}
\hline \multirow[b]{2}{*}{ Groups } & \multicolumn{2}{|c|}{$\begin{array}{l}\text { Total number } \\
\text { of head dips }\end{array}$} & \multicolumn{2}{|c|}{$\begin{array}{c}\text { Percent of head } \\
\text { dips in baited hole }\end{array}$} & \multicolumn{2}{|c|}{$\begin{array}{l}\text { Student's } t \text {-test on the percentage } \\
\text { of head dips in baited hole }\end{array}$} \\
\hline & D1 & D2 & \%D1 & \%D2 & D1 vs D2 & vehicle vs doses \\
\hline Vehicle $n=20$ & $56.5 \pm 1.7$ & $64.9 \pm 1.4$ & $60.7 \pm 2.8$ & $56.5 \pm 4.9$ & $t=0.739, \mathrm{NS}$ & \\
\hline $1 \mathrm{mg} / \mathrm{kg} n=18$ & $63.7 \pm 4.2$ & $62.8 \pm 6.2$ & $65.6 \pm 6.4$ & $67.8 \pm 3.8$ & $t=0.631, \mathrm{NS}$ & $\begin{array}{l}\text { for D1, } t=0.738, \mathrm{NS} \\
\text { for } \mathrm{D} 2, t=1.793, \mathrm{NS}\end{array}$ \\
\hline $0.25 \mathrm{mg} / \mathrm{kg} n=18$ & $60.1 \pm 3.8$ & $65.4 \pm 4.4$ & $58.4 \pm 8.1$ & $62.4 \pm 5.5$ & $t=0.413, \mathrm{NS}$ & $\begin{array}{l}\text { for } \mathrm{D} 1, t=0.283, \mathrm{NS} \\
\text { for } \mathrm{D} 2, t=0.802, \mathrm{NS}\end{array}$ \\
\hline
\end{tabular}

There is no significant between groups difference. 


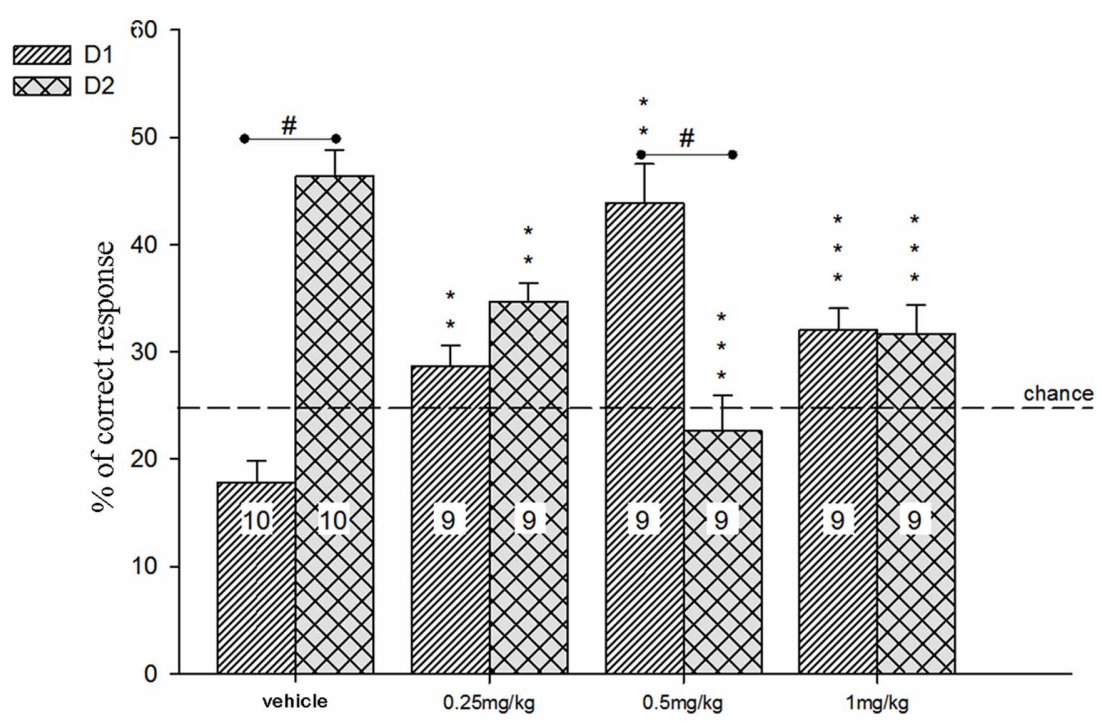

FIGURE 2 | Effect of stress on contextual memory in vehicle and diazepam $\mathbf{( 0 . 2 5}, \mathbf{0 . 5}$, and $\mathbf{1} \mathbf{~} \mathbf{g} / \mathbf{k g})$ treated mice. Memory performance was evaluated by the percentage of correct responses for D1 and D2 in the CSD task. Each animal were evaluated either on the D1 either on D2. All groups received ip injection (vehicle or diazepam) 30 min before the stress delivery. All animals were evaluated $15 \mathrm{~min}$ after the stress delivery. Numbers of animals used for each group are mentioned in histograms. Comparison to vehicle groups: ${ }^{*} p \leq 0.05$; ${ }^{* *} p \leq 0.01 ;{ }^{* * *} p \leq 0.001$. Dotted lines represent chance level. chance level for D2 (34.6 $\pm 6.3 \% ; t=5.434$; $p \leq 0.001)$. Bonferroni's $t$-test did not reveal any differences between D1 and D2 (28.7 \pm 5.7 and $34.6 \pm 6.3 \%$ respectively; $t=1.631$; NS). In addition, cross-analyses were performed as compared to vehicle-treated group on independent groups of mice. Inter-group comparisons evidenced a significant difference for D1 performance between the vehicle-treated and the $0.25-\mathrm{mg} / \mathrm{kg}$ groups $(17.8 \pm 2.5$ and $28.7 \pm 5.7 \%$ respectively; $t=3.042 ; p \leq 0.01)$. Furthermore, a significant difference for D2 performance was already observed between the vehicle-treated and the $0.25-\mathrm{mg} / \mathrm{kg}$ groups $(46.3 \pm 2.5$ and $34.6 \pm 6.3 \%$ respectively; $t=3.284 ; p \leq 0.01)$.

(iii) Diazepam $0.5 \mathrm{mg} / \mathrm{kg}$. Within-group analyses showed that D1 performance in $0.5 \mathrm{mg} / \mathrm{kg}$ treated mice was significantly above chance level $(43.8 \pm 3.7 \% ; t=5.090 ; p \leq 0.001)$ but was at chance for D2 $(22.6 \pm 3.3 \% ; t=0.719$; NS). Bonferroni's $t$-test revealed a significant differences between D1 and D2 performance in $0.5 \mathrm{mg} / \mathrm{kg}$ treated mice $(43.8 \pm 3.7$ and $22.6 \pm 3.3 \%$ respectively; $t=5.799 ; p \leq 0.001)$. In addition, cross-analyses were performed as compared to vehicletreated group on independent groups of mice. Inter-group comparisons evidenced a significant difference for D1 performance between the vehicle-treated and the $0.5-\mathrm{mg} / \mathrm{kg}$ groups $(17.8 \pm 2.5$ and $43.8 \pm 3.7 \%$ respectively; $t=7.286$; $p \leq 0.001)$. Furthermore, a significant difference for D2 performance was already observed between the vehicle-treated and the $0.5-\mathrm{mg} / \mathrm{kg}$ groups $(46.3 \pm 2.5$ and $22.6 \pm 3.3 \%$ respectively; $t=6.662 ; p \leq 0.001)$.

(iv) Diazepam $1 \mathrm{mg} / \mathrm{kg}$. The $1-\mathrm{mg} / \mathrm{kg}$ treated-mice exhibited significant memory performance for D1 and D2 as compared to chance level $(25 \% ; 32.1 \pm 1.9 \% ; t=3.576 ; p \leq 0.01$ and $31.7 \pm 2.7 \%$; $t=2.513 ; p \leq 0.05$ respectively as compa- red to chance level). Bonferroni's $t$-test did not reveal any difference between D1 and D2 (32.1 \pm 1.9 and $31.7 \pm 2.7 \%$ respectively; $t=0.103$; NS). In addition, inter-group comparisons evidenced a significant difference for D1 performance between the vehicle-treated and the $1-\mathrm{mg} / \mathrm{kg}$ groups $(17.8 \pm 2.5$ and $32.1 \pm 1.9 \%$ respectively; $t=3.990$; $p \leq 0.001)$. Furthermore, a significant difference for D2 performance was already observed between the vehicle-treated and the $1-\mathrm{mg} / \mathrm{kg}$ groups $(46.3 \pm 2.5$ and $31.7 \pm 2.7 \%$ respectively; $t=4.114 ; p \leq 0.001)$.

\section{Elevated plus-maze task}

Results are represented in Figure 3. Diazepam administration in stressed middle-aged mice induced a significant decrease of entry ratio as compared to placebo $(39.9 \pm 5.0 \%)$ for the dose of $0.5 \mathrm{mg} / \mathrm{kg}(58.9 \pm 2.3 \% ; p<0.01)$ and $1.0 \mathrm{mg} / \mathrm{kg}(54.7 \pm 3.1 \%$; $p<0.05)$. In contrast, diazepam at $0.25 \mathrm{mg} / \mathrm{kg}$ did not significantly modified performance as compared to vehicle ( $46.9 \pm 2.3 \%$; NS).

\section{EXPERIMENT 2: HIPPOCAMPAL CORTICOSTERONE LEVELS Basal levels}

The basal corticosterone levels in the dialyzate have been analyzed according to the further random attribution of mice to vehicle or diazepam-treated groups.

Basal corticosterone levels in the dialyzate obtained from vehicletreated mice were $2.71 \pm 0.48 \mathrm{nmol} / \mathrm{l}(n=8), 2.29 \pm 0.56 \mathrm{nmol} / \mathrm{l}$ $(n=8)$ for $0.25 \mathrm{mg} / \mathrm{kg}, 1.51 \pm 0.49 \mathrm{nmol} / \mathrm{l}(n=8)$ for $0.5 \mathrm{mg} / \mathrm{kg}$, $1.77 \pm 0.15 \mathrm{nmol} / \mathrm{l}(n=8)$ for $1 \mathrm{mg} / \mathrm{kg}$. There were no significant differences in basal extracellular corticosterone levels between: (i) vehicle and $0.25 \mathrm{mg} / \mathrm{kg}$ treated mice $(t=0.567 ; \mathrm{NS}$ ), (ii) vehicle and $0.5 \mathrm{mg} / \mathrm{kg}$ treated mice ( $t=1.888$; NS), (iii) vehicle and $1 \mathrm{mg} / \mathrm{kg}$ treated mice $(t=1.857$; NS). 


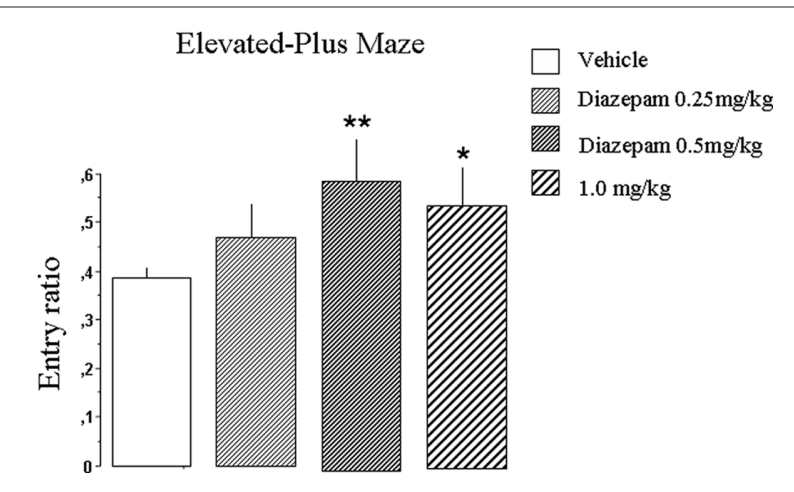

FIGURE 3 | Entry ratio in the elevated plus-maze task in vehicle and diazepam $(\mathbf{0 . 2 5}, \mathbf{0 . 5}$, and $\mathbf{1} \mathbf{~ m g} / \mathbf{k g})$ treated mice. As can be observed, diazepam at 0.5 and $1.0 \mathrm{mg} / \mathrm{kg}$ increased the entry ratio as compared to vehicles, ${ }^{*} p<0.01$; ${ }^{*} p<0.05$. The lower diazepam dose $(0.25 \mathrm{mg} / \mathrm{kg})$ induced no significant effect as compared to vehicles.

\section{Effect of stress}

Figure 4 represents corticosterone levels in the dorsal HPC. Results are expressed in percentage of variation of baseline. Two-way repeated-measures ANOVAs performed on corticosterone kinetic evidenced a significant interaction between Treatments $\times$ Time $\left[F_{(13,364)}=2.801 ; p \leq 0.001\right]$. Bonferroni's $t$-test did not reveal any difference between the groups (vehicle, $1,0.5$, and $0.25 \mathrm{mg} / \mathrm{kg}$ ) in the pre-stress period for each factor.

- Vehicle. As compared to the last pre-stress sample $(120.42 \pm 25.01 \%$; "time $=0$ "), stress induced a fast and important increase in corticosterone levels from $15 \mathrm{~min}$ after stress $(223.77 \pm 34.23 \% ; t=4.009 ; p \leq 0.001)$ to $120 \mathrm{~min}$ $(215.27 \pm 28.04 ; t=3.623 ; p \leq 0.01)$.

- $\quad 0.25 \mathrm{mg} / \mathrm{kg}$. During the post-stress period, stress induced a fast and rapid increase in corticosterone levels from $15 \mathrm{~min}$ after stress $(203.36 \pm 25.52 \% ; t=3.895 ; p \leq 0.01)$ to $105 \mathrm{~min}$ $(190.56 \pm 47.28 \% ; t=3.254 ; p \leq 0.01)$ as compared to the last pre-stress sample $(113.52 \pm 18.10 \%$; “time $=0$ "). Only the 120 point was no significant $(184.03 \pm 35.09 \% ; t=1.258$; NS) with the last pre-stress sample $(113.52 \pm 18.10 \%$; "time $=0$ "). Furthermore, after the stress delivery, the increase in corticosterone levels observed in $0.25 \mathrm{mg} / \mathrm{kg}$ diazepam-treated mice and vehicle-treated mice showed non-significant differences during all the post-stress period (NS in all comparisons).

- $0.5 \mathrm{mg} / \mathrm{kg}$. As compared to the last pre-stress sample $(91.23 \pm 14.09 \%$; "time $=0$ "), stress induced a progressive, and significant increase in corticosterone levels from $15 \mathrm{~min}$ after stress $(169.89 \pm 25.47 \% ; t=3.004 ; p \leq 0.05)$ to $75 \mathrm{~min}$ (191.21 $\pm 18.71 \% ; t=3.819 ; p \leq 0.01)$. Furthermore, the highest difference was observed $60 \mathrm{~min}$ after stress administration $(243.51 \pm 23.93 ; t=5.817 ; p \leq 0.001)$.

In addition, a faster increase in corticosterone levels in vehicletreated mice was observed 15 min after stress delivery as compared $0.5 \mathrm{mg} / \mathrm{kg}$ diazepam-treated mice $(223.77 \pm 34.23$ and $169.89 \pm 25.47 \%$, respectively; $t=2.414 ; p \leq 0.05)$ as well as $30 \mathrm{~min}$ after stress delivery $(238.22 \pm 24.60$ and $166.62 \pm 15.50 \%$, respectively; $t=2.295 ; p \leq 0.05)$. In contrast, no significant difference was observed between vehicle and $0.5 \mathrm{mg} / \mathrm{kg}$ diazepamtreated mice 45, 60,75, and 90 min after stress delivery (NS in all comparisons). Finally, a faster decrease of corticosterone levels in $0.5 \mathrm{mg} / \mathrm{kg}$ diazepam-treated mice was observed as regards to vehicle-treated mice for the 105-min point (172.45 \pm 37.95 and $232.86 \pm 26.74 \%$, respectively; $t=2.690 ; p \leq 0.05)$.

- $1 \mathrm{mg} / \mathrm{kg}$. As compared to the last pre-stress sample $(107.78 \pm 8.58 \%$; "time $=0$ "), the stress-induced rise in corticosterone levels was not observed in $1 \mathrm{mg} / \mathrm{kg}$ diazepam-treated mice.

In consequence, the significant fast and important increase in corticosterone levels in vehicle-treated mice was observed $15 \mathrm{~min}$ to the end of the post-stress delay, as compared to $1 \mathrm{mg} /$ $\mathrm{kg}$ diazepam-treated mice $(223.77 \pm 34.23$ and $89.63 \pm 10.61 \%$, respectively; $t=4.575 ; p \leq 0.001$ for 15 post-stress delay; $215.27 \pm 28.04$ and $104.35 \pm 23.27 \%$, respectively; $t=3.738$; $p \leq 0.001$ for 120 post-stress delay).

\section{DISCUSSION}

The main findings of our study are as follows:

(i) Diazepam significantly decreases anxiety-like reactivity in the elevated plus maze, at the doses of 0.5 and $1.0 \mathrm{mg} / \mathrm{kg}$ (but not at the dose of $0.25 \mathrm{mg} / \mathrm{kg}$ ), as compared to stressed vehicle-injected animals.

(ii) Stressed middle-aged mice exhibit a highly significant memory of the second discrimination (D2), while responding at chance (25\%) for the first one (D1). Diazepam administration at $0.5 \mathrm{mg} / \mathrm{kg}$ totally reverses the memory retrieval pattern in acutely stressed middle-aged animals (D1 > D2). In contrast, animals receiving the lowest $(0.25 \mathrm{mg} / \mathrm{kg})$ and highest $(1.0 \mathrm{mg} / \mathrm{kg})$ diazepam doses exhibit similar memory performance for both discriminations even though just above chance level.

(iii) Microdialysis experiment shows a significant interaction between diazepam doses and corticosterone concentrations into the HPC. From 0.25 to $0.5 \mathrm{mg} / \mathrm{kg}$, diazepam dose-dependently reduces intra-HPC corticosterone concentrations and in parallel, dose-dependently increased hippocampal memory performance in the CSD task. In contrast, the highest diazepam dose $(1.0 \mathrm{mg} / \mathrm{kg})$ induces a reduction in hippocampal corticosterone concentration, which was of greater magnitude as compared to the two other diazepam doses, but however decreased the hippocampal-dependent memory performance (D1) in the CSD task.

Our previous data (Chauveau et al., 2008, 2010; Tronche et al., 2010a,b) showed that both stress and aging, as well as hippocampal chemical lesions, selectively reduced the retrieval of D1 to chance level $(25 \%)$ while sparing the retrieval of D2. In the present study, we focused on stressed condition only insofar as stressed middle-aged mice exhibit memory retrieval pattern comparable to non-stressed middle-aged animals, except that stressed subjects exhibit an increase of D2 response of greater magnitude as compared to non-stressed ones. Thus, since our goal was only to determine if diazepam is able to restore a 


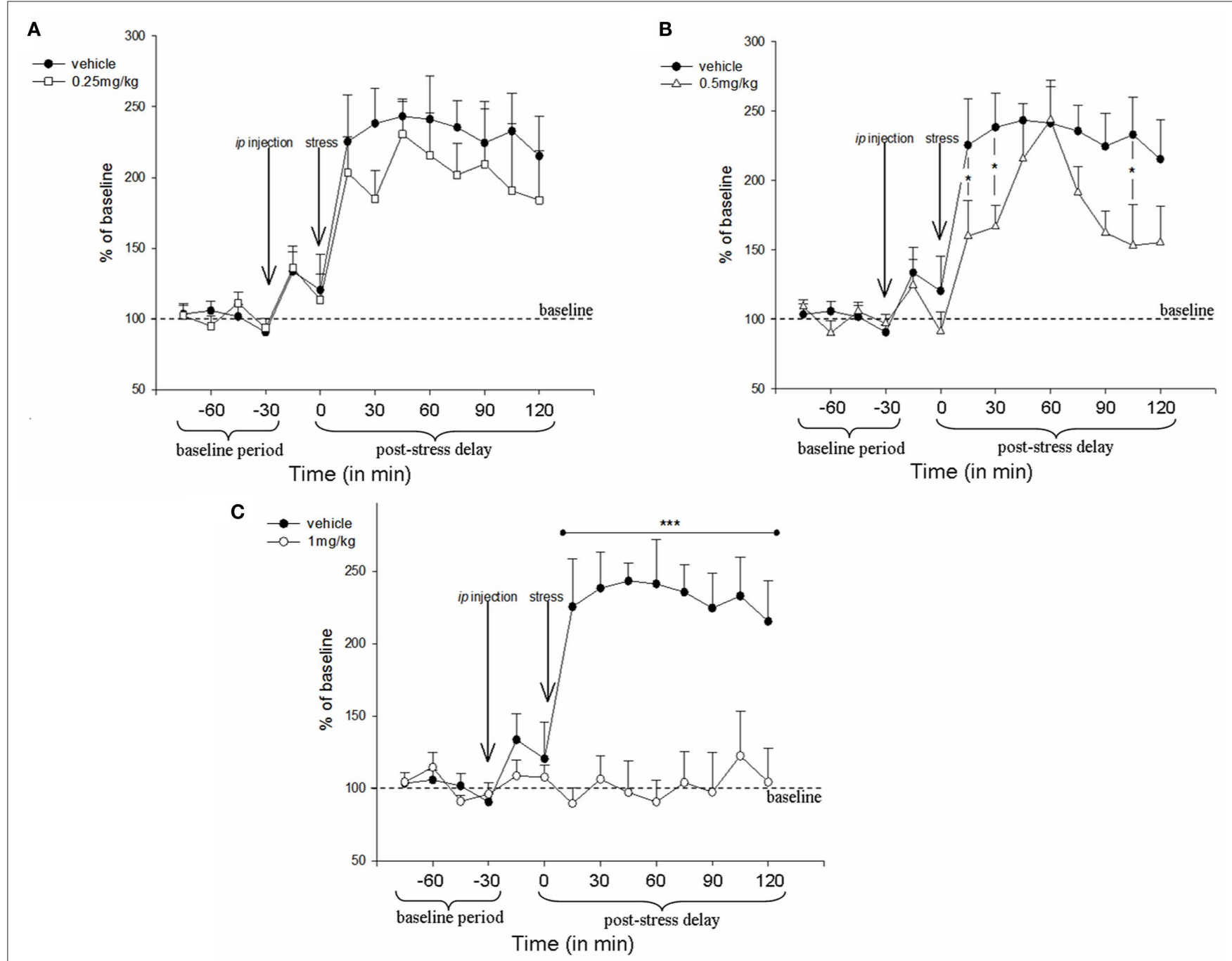

FIGURE 4 | Effect of stress on corticosterone concentration into the dorsal HPC. (A) Effect of $0.25 \mathrm{mg} / \mathrm{kg}$ diazepam on corticosterone concentration into the dorsal HPC after stress delivery. (B) Effect of $0.5 \mathrm{mg} / \mathrm{kg}$ diazepam on corticosterone concentration into the dorsal HPC after stress delivery. (C) Effect of $1 \mathrm{mg} / \mathrm{kg}$ diazepam on corticosterone concentration into the dorsal HPC after stress delivery. Numbers of animals used for each group are mentioned in graphs legends. Dotted lines represent baseline level. Comparisons to vehicle-treated animals: ${ }^{*} p \leq 0.05 ;{ }^{* *} p \leq 0.01 ;{ }^{* *} p \leq 0.001$. memory retrieval pattern comparable to the level of the one observed in young non-stressed mice (that is to say is able to restore the hippocampal-dependent D1 response), we decided therefore to analyze the effects of diazepam only in the more deleterious condition (middle-aged stressed mice) as compared to non-stress condition.

Our present study confirms the therapeutic anxiolytic action of diazepam. However, in our experimental conditions, this effect is more important for the dose of $0.50 \mathrm{mg} / \mathrm{kg}(p<0.01)$, as compared to $1.0 \mathrm{mg} / \mathrm{kg}(p<0.05)$. Data from the elevated plus-maze test also shows the absence of any sedative effect of diazepam on locomotion for the range of the doses used in our study.

We already showed that the memory retrieval of the first discrimination (D1) but not of the second one (D2) is dependent on the HPC activity, and that both stress and aging affected the memory retrieval of D1 but not of D2 (Celerier et al., 2004; Chauveau et al., 2008, 2009, 2010; Tronche et al., 2010a,b). Moreover, we also showed previously that in non-stress condition, aging increases HPC corticosterone concentration and abolished the HPC-dependent memory retrieval pattern, as compared to non-stressed young adult mice (Tronche et al., 2010a,b). Thus, acute stress amplified such endocrinal and cognitive effects of aging, as compared to the non-stress condition.

Our present data evidences a significant memory-enhancing effect of diazepam on HPC-dependent memory performance at the dose of $0.5 \mathrm{mg} / \mathrm{kg}$ in stressed middle-aged mice. This finding is at first sight surprising, because of the well-known anterograde and retrograde amnesic properties of BDZ in healthy young adult subjects (for review, Beracochea, 2006). However, the memoryenhancing effect observed in the present study as compared to both control animals and chance level for the dose of $0.5 \mathrm{mg} / \mathrm{kg}$ may rely on the specificity of the studied population, that is to say stressed middle-aged subjects. The microdialysis experiment shows that diazepam dose-dependently reduces HPC corticosterone 
concentrations but the memory-enhancing effect is observed only at the $0.5-\mathrm{mg} / \mathrm{kg}$ dose. In contrast, whereas the $1.0-\mathrm{mg} / \mathrm{kg}$ dose continues to decrease HPC corticosterone concentration, there is a decrease of HPC-dependent memory performance as compared to the $0.5-\mathrm{mg} / \mathrm{kg}$ diazepam dose (see Figure 5). Thus, the result found with the highest diazepam dose confirms a pejorative effect of diazepam on HPC-dependent memory performance, as compared to the $0.5-\mathrm{mg} / \mathrm{kg}$ dose.

In addition to the effects of diazepam on hippocampal corticosterone, other actors could also be involved in the dose-dependent effect of BDZ on memory in stress condition, mainly catecholamine, GABA, glutamate, and aspartate. Moreover, changes in $\mathrm{GABA} / \mathrm{BDZ}$ receptor number and affinity (desensitization) could also be involved.

As shown in Figure 5, a key finding is the continuous decrease in HPC corticosterone concentration measured $15 \mathrm{~min}$ after stress, as a function of the administered dose of diazepam. From a dynamic point of view (Figure 4), the highest diazepam dose totally inhibits the stress-induced HPC corticosterone rise. However, for the $0.50-\mathrm{mg} / \mathrm{kg}$ dose, diazepam attenuates the stress-induced corticosterone rise as compared to vehicle-treated animals and accelerates the return to baseline.

From a cognitive point of view, Figure 5 also shows a bimodal effect of diazepam as a function of the administered dose. Indeed, from 0.0 to $0.5 \mathrm{mg} / \mathrm{kg}$, we observed an inverse relationship between HPC-dependent memory performance and HPC corticosterone concentration. In contrast, from 0.50 to $1.0 \mathrm{mg} / \mathrm{kg}$, the memory performance varies in the same way as the HPC corticosterone level.

The action of diazepam on HPC corticosterone concentrations and memory performance could be explained via the interaction between the GABAergic system and HPC corticosterone as a result of the modulation of HPA axis activity by diazepam.

Indeed, numerous data have clearly demonstrated that HPA axis activity is regulated by non-glucocorticoid inhibitors. There is evidence that HPC-mediated mechanisms of glucocorticoid feedback could involve hypothalamic CRH secretion and GABAergic pathways (Calogero et al., 1988; Arvat et al., 2002; Cullinan et al., 2008).

$\Delta$ Corticosterone concentrations $\square$ Memory performance

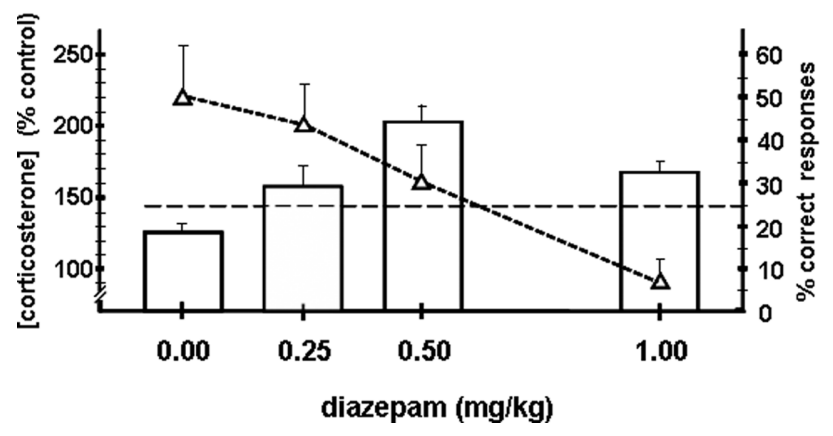

FIGURE 5 | Synoptic view of the effects of diazepam on both hippocampus corticosterone concentrations (left) and memory performance (D1 test; right). Comments are mentioned in the text.
Benzodiazepines (BDZ) activate central GABA receptors, which are importantly distributed in the HPC (Laviv et al., 2010; Lehner et al., 2010). It has been hypothesized that the effects of GABA/BDZ on HPA activity are mediated by CRH and/or AVP (see Cullinan et al., 2008).

The neurotransmitter GABA is a well-known inhibitor of ACTH release (Makara and Stark, 1974), probably through a central action on hypothalamic CRH. In vivo injection of the GABA-A receptor antagonist bicuculline into the dorsomedial hypothalamus resulted in increased plasma ACTH and corticosterone (Keim and Shekhar, 1996). Thus, the HPA axis appears to be under tonic GABA inhibition at the hypothalamic level, mediated through GABA receptors (Häusler et al., 1993). Moreover, neuroanatomical and pharmacological studies have established GABA-mediated inhibition of the HPA axis at the level of the PVN (Cullinan et al., 2008). Our study is however the first to evidence an in vivo direct dynamic interaction between $\mathrm{BDZ}$ and corticosterone level in the hippocampus in stress condition.

Glucocorticoids can impair HPC long term potentiation (LTP) in vitro (Dubrovsky et al., 1987; Pavlides et al., 1993) as well as increasing after hyperpolarization mediated by small conductance calcium-activated potassium channels (Joëls and de Kloet, 1989) that have been implicated in arousal. Because of the "inverted-U" response to these hormones (Diamond et al., 1992), low concentrations maintain, moderate concentrations promote, and high concentrations impair neuronal function. LTP is dependent on adrenal output in vivo, and adrenalectomy results in a significant decrease in the extent of LTP (Shors et al., 1990). Conversely, stress and excess glucocorticoids impair neuronal function and HPCdependent memory (reviewed by Sapolsky et al., 1986; de Kloet et al., 1991; Filipini et al., 1991; McEwen and Sapolsky, 1995; Lupien and McEwen, 1997).

So far, the bimodal modulation of HPC-dependent memory performance according to corticosterone concentrations is in agreement with the study of Diamond et al. (1992), showing that corticosterone exerts a concentration-dependent biphasic influence on the expression of hippocampal plasticity.

\section{CONCLUSION}

Our data evidences a direct interaction between diazepam, HPC corticosterone concentrations, and HPC-dependent memory performance in stressed middle-aged mice. To our knowledge, it is shown here for the first time that diazepam restores memory performance sustained by the hippocampus as previously evidenced (Chauveau et al., 2010) so that stressed middle-aged animals receiving the $0.5-\mathrm{mg} / \mathrm{kg}$ diazepam dose exhibit a memory pattern similar to the one of young adult non-stressed mice. This effect is related to the level of HPC corticosterone. Overall, our data illustrate how stress and benzodiazepines could modulate cognitive functions depending on hippocampus activity.

\section{ACKNOWLEDGMENTS}

The authors would like to thanks Dr. Frances Ash for language translation (contact: ashberac@free.fr). This research was supported by a grant (Opération No. 03 co015-05-PEA 010801) from the Délégation Générale pour l'Armement (DGA/DET/SCET/CEP/ SHP, Paris, France) and by the CNRS. 


\section{REFERENCES}

Arvat, E., Giordano, R., Grottoli, S., and Ghigo, E. (2002). Benzodiazepines and anterior pituitary function. $J$. Endocrinol. Invest. 25, 735-747.

Beracochea, D. (2006). Anterograde and retrograde effects of benzodiazepines on memory. Scientific World Journal 6, 1460-1465.

Calogero, A. E., Gallucci, W. T., Chrousos, G. P., and Gold, P. W. (1988). Interaction between GABAergic neurotransmission and rat hypothalamic corticotropin-releasing hormone secretion in vitro. Brain Res. 463, 28-36.

Cappell, A., Gmeindl, L., and ReuterLorenz, P. A. (2010). Age differences in prefrontal recruitment during verbal working memory maintenance depend on memory load. Cortex 46, 462-473.

Celerier, A., Pierard, C., Rachbauer, D., Sarrieau, A., and Beracochea, D. (2004). Contextual and serial discriminations: a new learning paradigm to assess simultaneously the effects of acute stress on retrieval of flexible or stable information in mice. Learn. Mem. 11, 196-204.

Chauveau, F., Pierard, C., Tronche, C., Coutan, M., Drouet, I., Liscia, P., and Beracochea, D. (2009). The HPC and prefrontal cortex are differentially involved in serial memory retrieval in non-stress and stress conditions. Neurobiol. Learn. Mem. 91, 447-455.

Chauveau, F., Tronche, C., Pierard, C., Coutan, M., Drouet, I., Liscia, P., and Beracochea, D. (2008). Prefrontal cortex or basolateral amygdala lesions blocked the stress-induced inversion of serial memory retrieval pattern in mice. Neurobiol. Learn. Mem. 90, 395-403.

Chauveau, F., Tronche, C., Pierard, C., Liscia, P., Drouet, I., Coutan, M., and Beracochea, D. (2010). Rapid stressinduced corticosterone rise in the HPC reverses serial memory retrieval pattern. HPC. Hippocampus 20, 196-207.

Comijs, H. C., Gerritsen, L., Penninx, B. W., Bremmer, M. A., Deeg, D. J., and Geerlings, M. I. (2010). The association between serum cortisol and cognitive decline in older. Am. J. Geriatr. Psychiatry 18, 42-50.

Cullinan, W. E., Ziegler, D. R., and Herman, J. P. (2008). Functional role of local GABAergic influences on the HPA axis. Brain Struct. Funct. 213, 63-72.

de Kloet, E. R., Sutanto, W., Rots, N., van Haarst, A., van den Berg, D., Oitzl, M., van Eekelen, A., and Voorhuis, D. (1991). Plasticity and function of brain corticosteroid receptors during aging. Acta Endocrinol. 125(Suppl. 1), 65-72. de Quervain, D. J., Henke, K., Aerni, A., Treyer, V., McGaugh, J. L., Berthold, T.,
Nitsch, R. M., Buck, A., Roozendaal, B., and Hock, C. (2003). Glucocorticoidinduced impairment of declarative memory retrieval is associated with reduced blood flow in the medial temporal lobe. Eur. J. Neurosci. 17, 1296-1302.

Diamond, D. M., Bennett, M. C., Fleshner, M., and Rose, G. M. (1992). Inverted-U relationship between the level of peripheral corticosterone and the magnitude of hippocampal primed burst potentiation. Hippocampus 4, 421-430.

Dubrovsky, B. O., Liquornik, M. S., Noble, P., and Gijsbers, K. (1987). Effects of 5 alpha-dihydrocorticosterone on evoked responses and long-term potentiation. Brain Res. Bull. 19, 635-638.

Filipini, D., Gijsbers, K., Birmingham, M. K., and Dubrovsky, B. (1991). Effects of adrenal steroids and their reduced metabolites on hippocampal longterm potentiation. J. Steroid Biochem. Mol. Biol. 40, 87-92.

Grottoli, S., Giordano, R., Maccagno, B. Pellegrino, M., Ghigo, E., and Arvat, E. (2002). The stimulatory effect of canrenoate, a mineralocorticoid antagonist, on the activity of the hypothalamus-pituitary-adrenal axis is abolished by alprazolam, a benzodiazepine, in humans. J. Clin. Endocrinol. Metab. 87, 4616-4620.

Häusler, A., Monnet, G., and Peter, O. (1993). Involvement of GABAB receptors in the regulation of the hypothalamo-pituitary-adrenocortical (HPA) axis in rats. J. Steroid Biochem. Mol. Biol. 46, 767-771.

Hillhouse, E. W., and Milton, N. G. (1989). Effect of noradrenaline and gammaaminobutyric acid on the secretion of corticotrophin-releasing factor-41 and arginine vasopressin from the rat hypothalamus in vitro. J. Endocrinol. 122, 719-723.

Imaki, T., Wang, X. Q., Shibasaki, T., Harada, S., Chikada, N., Takahashi, C., Naruse, M., and Demura, H. (1995). Chlordiazepoxide attenuates stress-induced activation of neurons, corticotropin-releasing factor (CRF) gene transcription and CRF biosynthesis in the paraventricular nucleus (PVN). Brain Res. Mol. Brain Res. 32, 261-270.

Joëls, M., and de Kloet, E. R. (1989). Effects of glucocorticoids and norepinephrine on the excitability in the hippocampus. Science 245, 1502-1505.

Jones, M. T., Gillham, B., Altaher, A. R., Nicholson, S. A., Campbell, E. A., Watts, S. M., and Thody, A. (1984). Clinical and experimental studies on the role of GABA in the regulation of ACTH secretion: a review. Psychoneuroendocrinology 9, 107-123.
Keim, S. R., and Shekhar, A. (1996). The effects of GABAA receptor blockade in the dorsomedial hypothalamic nucleus on corticotrophin (ACTH) and corticosterone secretion in male rats. Brain Res. 739, 46-51.

Laviv, T., Riven, I., Dolev, I., Vertkin, I., Balana, B., Slesinger, P.A., and Slutsky, I. (2010). Basal GABA regulates GABA(B)R conformation and release probability at single hippocampal synapses. Neuron 67, 253-267.

Lehner, M., WisŁowska-Stanek, A., Skórzewska, A., Maciejak, P., Szyndler, J., Turzy ska, D., Sobolewska, A., and PŁa nik, A. (2010). Differences in the density of GABA-A receptor alpha-2 subunits and gephyrin in brain structures of rats selected for low and high anxiety in basal and fear-stimulated conditions, in a model of contextual fear conditioning. Neurobiol. Learn. Mem. 94, 499-508.

Lupien, S. J., and McEwen, B. S. (1997) The acute effects of corticosteroids on cognition: integration of animal and human model studies. Brain Res. Brain Res. Rev. 24, 1-27.

Lupien, S. J., Nair, N. P., Briere, S., Maheu, F., Tu, M. T., Lemay, M., McEwen, B. S., and Meaney, M. J. (1999). Increased cortisol levels and impaired cognition in human aging: implication for depression and dementia in later life. Rev. Neurosci. 10, 117-139.

Makara, G. B., and Stark, E. (1974). Effects of gamma-aminobutyric acid (GABA) and GABA antagonist drugs on ACTH release. Neuroendocrinology 16, 178-190.

McEwen, B.S., and Sapolsky, R. M. (1995). Stress and cognitive function. Curr. Opin. Neurobiol. 5, 205-216.

Pardon, M. C. (2007). Stress and ageing interactions: a paradox in the context of shared etiological and physiopathological processes. Brain Res. Rev. 54, 251-273.

Pardon, M. C., and Ratray, I. (2008) What do we know about the longterm consequences of stress on ageing and the progression of agerelated neurodegenerative disorders? Neurosci. Biobehav. Rev. 32, 1103-1120.

Pavlides, C., Watanabe, Y., and McEwen, B. S. (1993). Effects of glucocorticoids on hippocampal long-term potentiation. Hippocampus 3, 183-192.

Paxinos, G., and Franklin, K. B. J. (2001). The Mouse Brain in Stereotaxic Coordinates, 2nd Edn. San Diego: Academic Press.

Pierard, C., Liscia, P., Chauveau, F., Coutan, M., Corio, M., Krazem, A., and Beracochea, D. (2010). Differential effects of total sleep deprivation on contextual and spatial memory: Modulatory effects of modafinil. Pharmacol. Biochem. Behav. 97, 399-405.

Piérard, C., Tronche, C., Liscia, P., Chauveau, F., and Béracochéa, D. (2009). Combined effects of acute stress and amphetamine on serial memory retrieval pattern in mice. Psychopharmacology (Berl.) 203, 463-473.

Sapolsky, R. M., Krey, L. C., and McEwen, B.S. (1986). The neuroendocrinology of stress and aging: the glucocorticoid cascade hypothesis. Endocr. Rev. 3, 284-301.

Shoji, H., and Mizoguchi, K. (2010). Aging-related changes in the effects of social isolation on social behavior in rats. Physiol Behav. 102, 58-62.

Shors, T. J., Levine, S., and Thompson, R. F. (1990). Effect of adrenalectomy and demedullation on the stress-induced impairment of long-term potentiation. Neuroendocrinology 51, 70-75.

Stotz-Potter, E. H., Willis, L. R., and DiMicco, J.A. (1996). Muscimol acts in dorsomedial but not paraventricular hypothalamic nucleus to suppress cardiovascular effects of stress. J. Neurosci. 16, 1173-1179.

Tronche, C., Pierard, C., Coutan, M., Chauveau, F., Liscia, P., and Beracochea, D. (2010a). Increased stress-induced intra-hippocampus corticosterone rise associated with memory impairments in middleaged mice. Neurobiol. Learn. Mem. 93, 343-351.

Tronche, C., Lestage, P., Louis, C., Carrie, I., and Beracochea, D. (2010b). Pharmacological modulation of contextual "episodic-like" memory in aged mice. Behav. Brain Res. 215, 255-260.

Conflict of Interest Statement: The authors declare that the research was conducted in the absence of any commercial or financial relationships that could be construed as a potential conflict of interest.

Received: 08 December 2010; paper pending published: 28 January 2011; accepted: 08 March 2011; published online: 12 April 2011.

Citation: Béracochéa D, Tronche C, Coutan $M$, Dorey $R$, Chauveau $F$ and Piérard $C$ (2011) Interaction between diazepam and hippocampal corticosterone after acute stress: impact on memory in middle-aged mice. Front. Behav. Neurosci. 5:14. doi: 10.3389/fnbeh.2011.00014

Copyright (c) 2011 Béracochéa, Tronche, Coutan, Dorey, Chauveau and Piérard. This is an open-access article subject to a non-exclusive license between the authors and Frontiers Media SA, which permits use, distribution and reproduction in other forums, provided the original authors and source are credited and other Frontiers conditions are complied with. 